\title{
Completion thyroidectomy via the transoral endoscopic vestibular approach
}

\author{
Christopher R. Razavi, Ralph P. Tufano, Jonathon O. Russell \\ Division of Head and Neck Endocrine Surgery, Department of Otolaryngology, Head and Neck Surgery, Johns Hopkins University School of \\ Medicine, Baltimore, MD, USA \\ Correspondence to: Jonathon O. Russell, MD. Department of Otolaryngology, Head and Neck Surgery, The Johns Hopkins School of Medicine, Johns \\ Hopkins Outpatient Center, 601 N. Caroline Street, 6th floor, Baltimore, MD 21287, USA. Email: jrusse41@jhmi.edu.
}

\begin{abstract}
The safety and efficacy of the transoral endoscopic thyroidectomy vestibular approach (TOETVA) continues to be verified with the growing literature in regards to the procedure. While early cases were thyroid lobectomies performed for benign disease, the indications for TOETVA have now expanded to include total thyroidectomy for select small well-differentiated thyroid cancers (DTCs). Oncologic efficacy of this procedure remains unproven at this time, as the procedure was described only recently. Furthermore, as many of the cases completed via TOETVA are often diagnostic lobectomies, the appropriate management for patients requiring or opting for further surgical intervention per American Thyroid Association (ATA) guidelines has not been established. Here we present a case of a diagnostic lobectomy via TOETVA followed by interval completion thyroidectomy via the same approach for minimally invasive Hurthle cell carcinoma. Postoperative ultrasound demonstrated no evidence of thyroid remnant and serum thyroglobulin without circulating anti-thyroid antibodies was $0.3 \mathrm{ng} / \mathrm{mL}$ (reference range, $1.5-38.5 \mathrm{ng} / \mathrm{mL}$ ) following the patient's completion thyroidectomy.
\end{abstract}

Keywords: Transoral thyroidectomy; remote-access thyroidectomy; completion thyroidectomy

Submitted Feb 02, 2018. Accepted for publication Feb 07, 2018.

doi: $10.21037 /$ gs.2018.02.01

View this article at: http://dx.doi.org/10.21037/gs.2018.02.01

\section{Introduction}

Over the last several years there has been increasing awareness of the desire to avoid a cervical neck incision when performing thyroid surgery $(1,2)$. Although the transcervical approach (TCA) to the thyroid has been utilized safely and effectively over the last century, neck scarring can negatively impact patient quality of life (3-5). As a result, several minimally invasive and remote access techniques have been utilized, including the transoral endoscopic thyroidectomy vestibular approach (TOETVA) (6-11). Indications for TOETVA continue to expand, and while most initial cases were lobectomies for benign disease, its application has extended to include total thyroidectomies for select, differentiated thyroid cancer (DTC) (12). Some surgeons have also begun to utilize this approach to perform concomitant prophylactic central neck dissections when they deem indicated $(10,13)$. However, as TOETVA was only recently described, we have yet to determine if there is oncologic equivalency with the traditional open approach in managing DTC. Moreover, as many patients meeting criteria for TOETVA often have indeterminate disease $(8,11)$, others question how to manage those requiring further surgical intervention following diagnostic transoral lobectomy, i.e., is the transoral approach oncologically sound for reoperative situations? Here we present a case of diagnostic lobectomy via TOETVA followed by interval completion thyroidectomy via the same technique for differentiated thyroid carcinoma.

\section{Case presentation}

A 39-year-old otherwise healthy female presented to her 


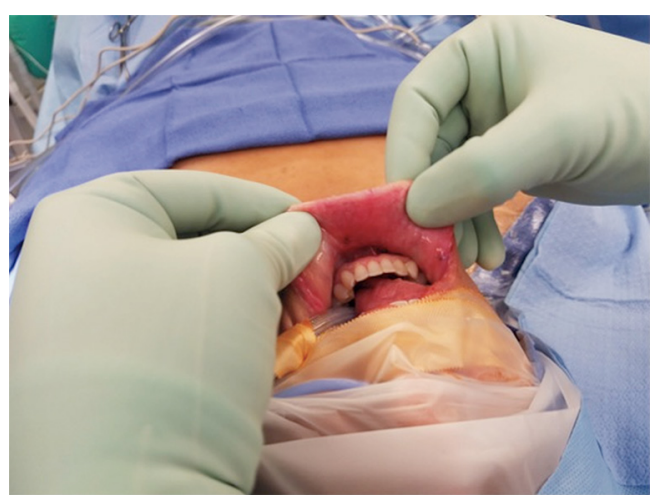

Figure 1 Intraoperative image demonstrating positioning for completion thyroidectomy via TOETVA. Trocars were placed at the same sites as the previous intraoral incisions, which are identified only by the remaining absorbable suture.

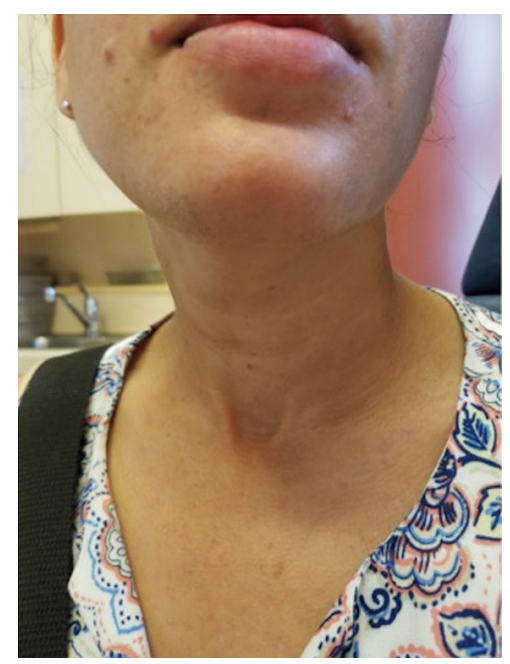

Figure 2 Postoperative image demonstrating the appearance of the patient's neck following her completion thyroidectomy.

primary care physician for routine examination where a thyroid nodule was palpated. She was euthyroid. She subsequently underwent thyroid ultrasound, which confirmed the presence of $2.4 \mathrm{~cm}$ solid nodule in the left mid-lower pole with cytopathology suspicious for Hurthle cell neoplasm (Bethesda IV). The right thyroid lobe was normal and the neck was without suspicious lymphadenopathy. She was referred to our service for surgical management because she wanted the nodule removed regardless of genomic testing being offered. She was presented with options for thyroid lobectomy $v s$. total thyroidectomy, with each intervention and possible consequences discussed in detail. She elected for left thyroid lobectomy with the understanding that she may need a completion thyroidectomy pending her final pathology. Of note, she was highly motivated to avoid a cervical incision, and as such she opted for a transoral approach after she was confirmed to meet inclusion criteria for TOETVA. She underwent left thyroid lobectomy via TOETVA without complication (operative time 116 minutes) and was discharged to home the same day. Final pathology demonstrated a $2.0 \mathrm{~cm}$ minimally invasive Hurthle cell carcinoma. Though it was explained that based on the 2015 American Thyroid Association (ATA) guidelines she did not require a completion thyroidectomy, she opted for further surgical management to facilitate followup and radioactive iodine therapy if deemed necessary. Again, it was reinforced to the patient that radioiodine is not generally the standard of care in such lesions, especially given her diagnosis of a minimally invasive Hurthle cell carcinoma, but after consulting with her endocrinologist she elected completion thyroidectomy to facilitate oncologic surveillance. She again wished to avoid a cervical neck incision, and she underwent right completion thyroidectomy via TOETVA 9 days following her initial procedure (Figure 1). To our knowledge, she was the first completion thyroidectomy via this approach in North America. The procedure was again completed without complication utilizing the same port placement from her initial procedure (operative time 94 minutes). There was no increased difficulty in dissection or in raising the subplatysmal flap despite her prior surgery. She was discharged to home the same day with a PTH of $58 \mathrm{pg} / \mathrm{mL}$ (reference range $10-65 \mathrm{pg} / \mathrm{mL}$ ) and her right thyroid lobe was found to be histopathologically normal on permanent section. On follow-up ultrasonography there was no thyroid remnant visible, and her thyroglobulin was $0.3 \mathrm{ng} / \mathrm{mL}$ (reference range, $1.5-38.5 \mathrm{ng} / \mathrm{mL}$ ). The patient was notably pleased with her final cosmetic outcome (Figure 2).

\section{Discussion}

We present, to our knowledge, the first interval completion thyroidectomy via TOETVA in North America with postoperative thyroid ultrasonography and thyroglobulin levels suggestive of a structural complete response. The patient suffered no cutaneous scarring, recurrent laryngeal/ mental nerve injury, or hypoparathyroidism as a result 
of either of her procedures. Furthermore, we did not appreciate any significant adhesions when performing subplatysmal flap dissection, or any distortion of anatomy as a result of the patient's initial transoral procedure. In fact, the patient's second procedure was 22 minutes shorter, which we attribute to decreased time raising the subplatysmal flap. As completion thyroidectomy procedures even via TCA are associated with a higher morbidity rate than the initial procedure (14), the outcomes of this case are encouraging and demonstrate the feasibility of completion thyroidectomy via TOETVA. A larger series is required to quantify the true safety and efficacy, and longer-term follow-up is necessary to understand the oncologic validity of this approach.

\section{Acknowledgements}

None.

\section{Footnote}

Conflicts of Interest: The authors have no conflicts of interest to declare.

Informed Consent: Written informed consent was obtained from the patient for publication of this manuscript and any accompanying images.

\section{References}

1. Berber E, Bernet V, Fahey TJ 3rd, et al. American Thyroid Association Statement on remote-access thyroid surgery. Thyroid 2016;26:331-7.

2. Davies L, Welch HG. Current thyroid cancer trends in the United States. JAMA Otolaryngol Head Neck Surg 2014;140:317-22.

3. Arora A, Swords C, Garas G, et al. The perception of scar cosmesis following thyroid and parathyroid surgery: A prospective cohort study. Int J Surg 2016;25:38-43.

4. Arora A, Garas G, Sharma S, et al. Comparing transaxillary robotic thyroidectomy with conventional surgery in a UK population: A case control study. Int J Surg 2016;27:110-7.

5. Choi Y, Lee JH, Kim YH, et al. Impact of postthyroidectomy scar on the quality of life of thyroid cancer patients. Ann Dermatol 2014;26:693-9.

6. Terris DJ, Singer MC, Seybt MW. Robotic facelift thyroidectomy: II. Clinical feasibility and safety. Laryngoscope 2011;121:1636-41.

7. Kandil EH, Noureldine SI, Yao L, et al. Robotic transaxillary thyroidectomy: An examination of the first one hundred cases. J Am Coll Surg 2012;214:558-64; discussion 564-6.

8. Russell JO, Clark J, Noureldine SI, et al. Transoral thyroidectomy and parathyroidectomy - A North American series of robotic and endoscopic transoral approaches to the central neck. Oral Oncol 2017;71:75-80.

9. Anuwong A. Transoral endoscopic thyroidectomy vestibular approach: a series of the first 60 human cases. World J Surg 2016;40:491-7.

10. Anuwong A, Ketwong K, Jitpratoom P, et al. Safety and outcomes of the transoral endoscopic thyroidectomy vestibular approach. JAMA Surg 2018;153:21-7.

11. Kim HY, Chai YJ, Dionigi G, et al. Transoral robotic thyroidectomy: lessons learned from an initial consecutive series of 24 patients. Surg Endosc 2018;32:688-94.

12. Razavi CR, Russell JO. Indications and contraindications to transoral thyroidectomy. Ann Thyroid 2017;2. doi: 10.21037/aot.2017.10.01.

13. Razavi CR, Fondong A, Tufano RP, et al. Central neck dissection via the transoral approach. Ann Thyroid 2017;2. doi: 10.21037/aot.2017.10.02.

14. Chao TC, Jeng LB, Lin JD, et al. Reoperative thyroid surgery. World J Surg 1997;21:644-7.
Cite this article as: Razavi CR, Tufano RP, Russell JO. Completion thyroidectomy via the transoral endoscopic vestibular approach. Gland Surg 2018;7(Suppl 1):S77-S79. doi: 10.21037/gs.2018.02.01 